\title{
Drug error - problem in anaesthesia
}

Editor, - Drug error is one of the major problems in anaesthesia and is an important cause of patient morbidity and mortality. Anaesthesia is considered to be quite safe now as compared to olden times but yet anaesthetists are not immune from making medication errors and the consequences of their mistakes may be serious as compared to other specialities. ${ }^{1}$ Haste, stress, drug labeling error, lack of sleep, communication failure, inexperienced assistants etc are few of the contributing factors. ${ }^{2}$ The drugs most commonly involved are neuromuscular blocking agents followed by opioids. ${ }^{2}$

We encountered an incidence of an error with an unexpected drug. A 40 year old ASA I patient was posted for fixation of fracture shaft of femur. Spinal anaesthesia was administered. After achieving a level up to T8, surgery was started. After a period of thirty minutes patient developed severe bradycardia and the heart rate was 35 beats/min. One prefilled syringe which was lying on the anaesthesia machine was immediately administered but the heart rate increased only up to 45 beats/min. Anaesthesia assistant was ordered to immediately load another ampoule of atropine. Following its administration, patient developed a tachycardia, 250 beats/min and the blood pressure rose to $220 / 140 \mathrm{mmHg}$ from a basal level of $110 / 70 \mathrm{mmHg}$. Patient started complaining of severe headache and palpitations and ECG showed ventricular tachycardia which reverted back following amiodarone injection. This atypical response of atropine was very astonishing. Broken drug ampoule was traced and it was found to be adrenaline instead of atropine. This accident occurred because of same size, same quantity and almost similar labels of both drugs (Figure $1)$.

A standardised colour code for user- applied syringe label for anaesthetic drugs exist in various countries. ${ }^{3}$ Various recommendations for minimizing drug error have been laid down from time to time.

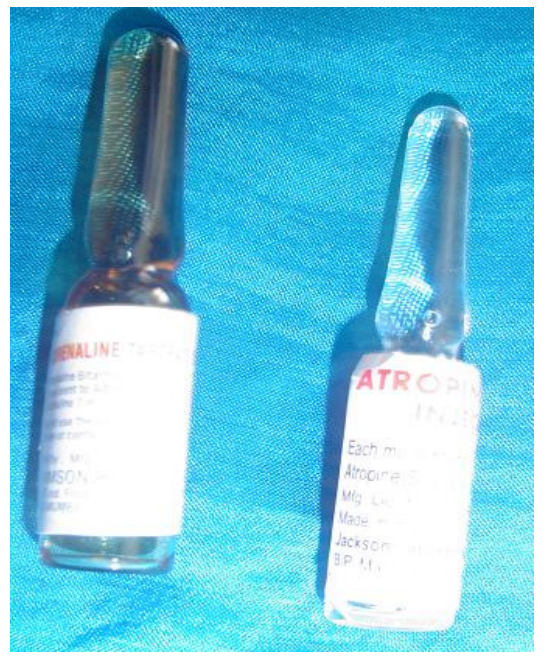

Figure 1

Ampoules of atropine and adrenalin

The label on any drug ampoule or syringe should be read carefully before a drug is drawn up or injected; contents of labels on ampoules and syringes should be optimised according to standards: syringe should always be labelled, formal organisations of drug drawers and work space should be used; and labels should be checked with a second person. $^{4}$

Various standards have been approved by ASA House of Delegates on October 27, 2004 for recognition and identification of an object depending upon shape, colour, brightness and contrast. ASA supports the manufacturer and use of pharmaceuticals with the label meeting the following standards, which are consistent with those established by American Society for Testing and Materials International (ASTM international) based on label contents, font and contrast background. Nine classes of drugs commonly used in anaesthesia practice have standard background established for user- applied syringe labels by ASTM international standard D14774. As per standards induction agents should be yellow, tranquilizer orange, muscle relaxant fluorescent red, narcotics blue, vasopressor violet, local anaesthetic gray, and anticholinergics green. ${ }^{5}$ 
Some centres have established principles of system that includes trays that promote a well organised anaesthetic work space, colour and bar code labelling of syringes and automatic visual and auditory verification of syringe labels by computer just before drug administration. ${ }^{6}$

We want to convey the message to all anaesthesia personnel about the drugs in which intermixing is common. But still further research is required into the effectiveness of preventive strategies. There should be further modification in designinig the drug labels and ampoule color by the pharmaceutical companies for safety and reduction in medication error.

Kiranpreet Kaur, Roop Singh, Sarla Hooda, Jatin Lal. Pt. B.D Sharma, PGIMS, Rohtak, Haryana, India.

\section{References:}

1. Wheeler SJ, Wheeler DW. "Medication error in anaesthesia and critical care". Anaesthesia 2005; 60(3): 257-273.

http://dx.doi.org/10.1111/j.1365$\underline{\text { 2044.2004.04062.x }}$

PMid:15710011

2. Abeysekera A, Bergman IJ, Kluger MT. Drug error in anaesthetic practice: a review of 896 reports from the Australian Incident Monitoring Study database. Anaesthesia 2005; 60(3): 220227.

http://dx.doi.org/10.1111/j.1365$\underline{2044.2005 .04123 . x}$

PMid:15710005

3. Christie I, Hill MR. Standardized colour coding for syringe drug label: A national survey. Anaesthesia 2002; 57(8):793-98. http://dx.doi.org/10.1046/j.13652044.2002.02698_3.x PMid:12133093

4. Jenson LS, Merry AF, Webster C, Weller J, Larson L. Evidence- based strategies for preventing drug administration errors during anaesthesia. Anaesthesia 2004; 59(5): 493-504. http://dx.doi.org/10.1111/j.13652044.2004.03670.x PMid:15096243

5. Statement on the labelling of pharmaceutical for use in anaesthesiology (Approved by ASA House of Delegates October 27, 2004)
WWw.astm.org.

6. Merry AF, Webster CS. A New safety oriented integrated drug administration and Automated Anaesthesia system. Quality and Safety in Health Care 2005; 14:e15. 